\title{
Quality of Life Improves with Individualized Home-based Exercises in Critical Care Survivors
}

\author{
Aayushi G. Shelly, Nivedita S. Prabhu, Priyanka Jirange, Asha Kamath¹, K. Vaishali \\ Department of Physiotherapy, School of Allied Health Sciences, Manipal University, ${ }^{1}$ Department of Community Medicine, Kasturba Medical College, \\ Manipal University, Manipal, Udupi, Karnataka, India
}

\section{Abstract}

The Aim of the Study: This study aims to determine the effect of individualized home-based exercise on the quality of life post-Intensive Care Unit (ICU) discharge. Subjects: Adult patients invasively mechanically ventilated for more than $48 \mathrm{~h}$ in medical ICU. Methodology: Thirty-five patients were enrolled prospectively in this study. They were interviewed to complete short form 36 (SF-36) version 2 questionnaire and were randomly allocated to control and experimental group by block randomization. The experimental group received individualized exercise information sheet and control group was asked to continue routine exercises done during their hospital stay. The experimental group also received a log book and weekly telephonic reminders. Patients were interviewed to complete the SF-36 through the telephone 4 weeks after hospital discharge. Results: Physical and mental components of the quality of life as measured by the SF-36 at the end of 4 weeks after hospital discharge showed a statistically significant difference $(P<0.05)$ in the experimental group. Conclusion: A well-structured individualized exercise program improves the quality of life of critically ill patients after discharge.

Keywords: Critical care rehabilitation, critical illness, home-based rehabilitation, Intensive Care Unit survivors, physiotherapy, short form 36

\section{INTRODUCTION}

The mortality of patients with acute lung injury is $35 \%-45 \%,{ }^{[1]} 50 \%-60 \%$ in patients with septic shock, ${ }^{[2]}$ and $7 \%$ for myocardial infarction with ST-elevation ${ }^{[3]}$ globally and continues to decline every year. Once the patient survives the phase of critical illness, he/she may experience numerous complications succeeding Intensive Care Unit (ICU) discharge. The residual problems can manifest as weakness, fatigue, breathlessness, anxiety, ${ }^{[4]}$ depression, ${ }^{[5]}$ posttraumatic reactions, ${ }^{[6]}$ and reduced cognitive function which collectively limits activities of daily living and subsequently leads to physical deconditioning. There is growing evidence that ICU survivors experience long-term physical, neurocognitive, and mental health complications directly associated with their experience during ICU stay. This broad spectrum of complications can altogether affect the physical, mental, and social wellbeing of the patient thereby affecting their quality of life. Health-related quality of life (HRQoL) is made up of physical, psychological, and social domains which

\begin{tabular}{|l|l|}
\hline \multicolumn{3}{|c|}{ Access this article online } \\
\hline Quick Response Code: & Website: \\
& www.ijccm.org \\
\hline
\end{tabular}

interact with each other and patient's perception. Short form 36 (SF-36) is the most widely used scale to assess the quality of life in critically ill patients. ${ }^{[7]}$ As the aftermath of critical illness, complications continues even at home, the quality of life may be compromised which necessitates the need for a hospital based and home-based exercise program after ICU discharge. Therefore, this study proposes a strong need to explore the effect of patient-specific home-based exercise on their quality of life of after being discharged from a critical care setting.

\section{Objective}

The objective of the study is to determine the effect of individualized home-based exercise on the quality of life post-ICU discharge.

Address for correspondence: Dr. K. Vaishali, Department of Physiotherapy, School of Allied Health Sciences, Manipal University, Manipal, Udupi - 576 104, Karnataka, India. E-mail: vaishali.kh@manipal.edu

This is an open access article distributed under the terms of the Creative Commons Attribution-NonCommercial-ShareAlike 3.0 License, which allows others to remix, tweak, and build upon the work non-commercially, as long as the author is credited and the new creations are licensed under the identical terms.

For reprints contact: reprints@medknow.com

How to cite this article: Shelly AG, Prabhu NS, Jirange P, Kamath A, Vaishali K. Quality of life improves with individualized home-based exercises in critical care survivors. Indian J Crit Care Med 2017;21:89-93. 


\section{Methodology}

A total of 144 subjects were screened, and 35 subjects were recruited in this study from medical Intensive Care Units who were invasively mechanically ventilated for $24 \mathrm{~h}$ and admitted for more than $48 \mathrm{~h}$ in the ICU in a tertiary care hospital between February 2014 and February 2015. Patients with musculoskeletal trauma, neurological deficits, psychological/ psychiatric disorders, malignancies, organophosphorus poisoning or substance abuse and having a history of ICU admission in the past 6 months were excluded from the study. The study protocol was approved by the Institutional Board of Ethics Committee. This study was enrolled in the clinical trial registry (CTRI/2015/09/006199). The license agreement was obtained from Quality Metric, Optum Insight company for using SF-36 version 2 (SF-36 v 2; License No. QM022571). All the eligible subjects were explained the procedure, and a written informed consent was obtained, from the patients who fulfilled the criteria and were willing to participate in the study. Patients were randomized using block randomization into two groups using concealed envelope. The participants in study group followed the medical intervention prescribed by the physician and individualized home-based exercises prescribed by the physiotherapist. The participants of control group followed the medical intervention prescribed by the physician without any formal exercise prescription.

Demographic data and detailed history of their comorbidities and intensive care unit stay were noted down. SF-36 v 2 questionnaire was administered within $48 \mathrm{~h}$ of ICU discharge. During the hospital stay, all participants in study and control group received routine physiotherapy. SF-36 v 2 was again administered in both groups at the time of discharge from the hospital setting. Participants in the study group received the routine physiotherapy in the hospital and underwent 4 weeks of home-based training post discharge. Before discharging from the hospital, these participants received an exercise information sheet and were familiarized with the prescribed exercises. This sheet contained a pictorial representation of the all the prescribed exercises with instructions in participant's preferred language. The exercises included in this sheet were a combination of respiratory and mobility exercises. Respiratory exercises comprised deep breathing exercises, thoracic expansion exercises, incentive spirometer (if available), pursed lip breathing, and forced expiratory maneuvers. Each exercise had to be repeated five times per session. Each session lasted for $15 \mathrm{~min}$. The exercises were performed five times a week. Mobility exercises mainly included active assisted or active exercises performed on the bed, dynamic Quadriceps, sitting out of bed, spot marching, and ambulation. Each active exercise was repeated for ten times per set. Ambulation was done twice a day based on perceived rate of exertion (11-13 on Borgs scale). Each session lasted for 15-20 min done for five times per week. Hence, a combination of respiratory and mobility exercise lasted for 30-40 min a session performed 5 days a week. To improve the adherence even the caregivers/bystanders of the participants were explained about the exercises which were to be performed by the participants at home. The quality of life using SF-36 v 2 was assessed telephonically after 4 weeks postdischarge from the hospital in both groups.

\section{Statistical analysis}

SPSS version 15 (SPSS Inc. Released 2006. SPSS for Windows, Version 15.0. Chicago, SPSS Inc.) was used for data analysis. Descriptive statistics was used to analyze demographic data. Test for normality was done using Shapiro-Wilk test. MannWhitney U-test was used to analyze the change in the quality of life between study and control group. Wilcoxon's signed rank test was performed to analyze the difference in the quality of life within the groups. Graphical representations were used to show the differences. The level of statistical significance was set at $P \leq 0.05$.

\section{RESULTS}

A total of 144 subjects were screened, and 35 subjects were recruited in this study [Figure 1]. The mean \pm standard deviation age of the subjects in this study was $54.50 \pm 10$ years. Baseline characteristics of the patients enrolled in the study and their clinical diagnosis are presented in Table 1 and 2.

When median change in scores of domains of physical component between groups was analyzed [Figure 2] there was a statistical significant difference seen in physical function $(P=0.003)$, role physical $(P=0.001)$, bodily pain $(P=0.004)$, general health $(P=0.017)$, and physical component summary (PCS) $(P=0.003)$ in the study group [Table 3].

When median change in scores of domains of mental component between groups was analyzed [Figure 3] there was a statistical significant difference seen in mental health $(P=0.008)$, role emotional $(P=0.001)$, social function $(P=0.008)$, vitality $(P=0.003)$, and mental component summary (MCS) score $(P=0.006)$ in the study group [Table 4$]$.

\section{Discussion}

Our study showed significant improvement in both physical

\begin{tabular}{|c|c|c|c|}
\hline Parameters & $\begin{array}{l}\text { Study group } \\
\quad(n=17)\end{array}$ & $\begin{array}{l}\text { Control group } \\
\quad(n=18)\end{array}$ & $P$ \\
\hline Age (years) & $59(50.5-65)$ & $53(42.75-56)$ & 0.089 \\
\hline Gender (male: female) & 11:6 & $10: 8$ & \\
\hline Hours of mechanical ventilation (h) & $144(84-212)$ & $162(120-220)$ & 0.208 \\
\hline Length of stay in ICU (days) & $8(6-11.5)$ & $9.5(7-12)$ & 0.273 \\
\hline Length of stay in hospital (days) & $13(9.50-17)$ & $13.50(12-16.2)$ & 0.476 \\
\hline $\begin{array}{l}\text { PCS score at ICU discharge } \\
(\text { mean } \pm \text { SD) }\end{array}$ & $30.09 \pm 4.59$ & $29.93 \pm 3.64$ & 0.47 \\
\hline $\begin{array}{l}\text { MCS score at ICU discharge } \\
(\mathrm{mean} \pm \mathrm{SD})\end{array}$ & $30.24 \pm 6.11$ & $30.18 \pm 4.82$ & 0.40 \\
\hline
\end{tabular}




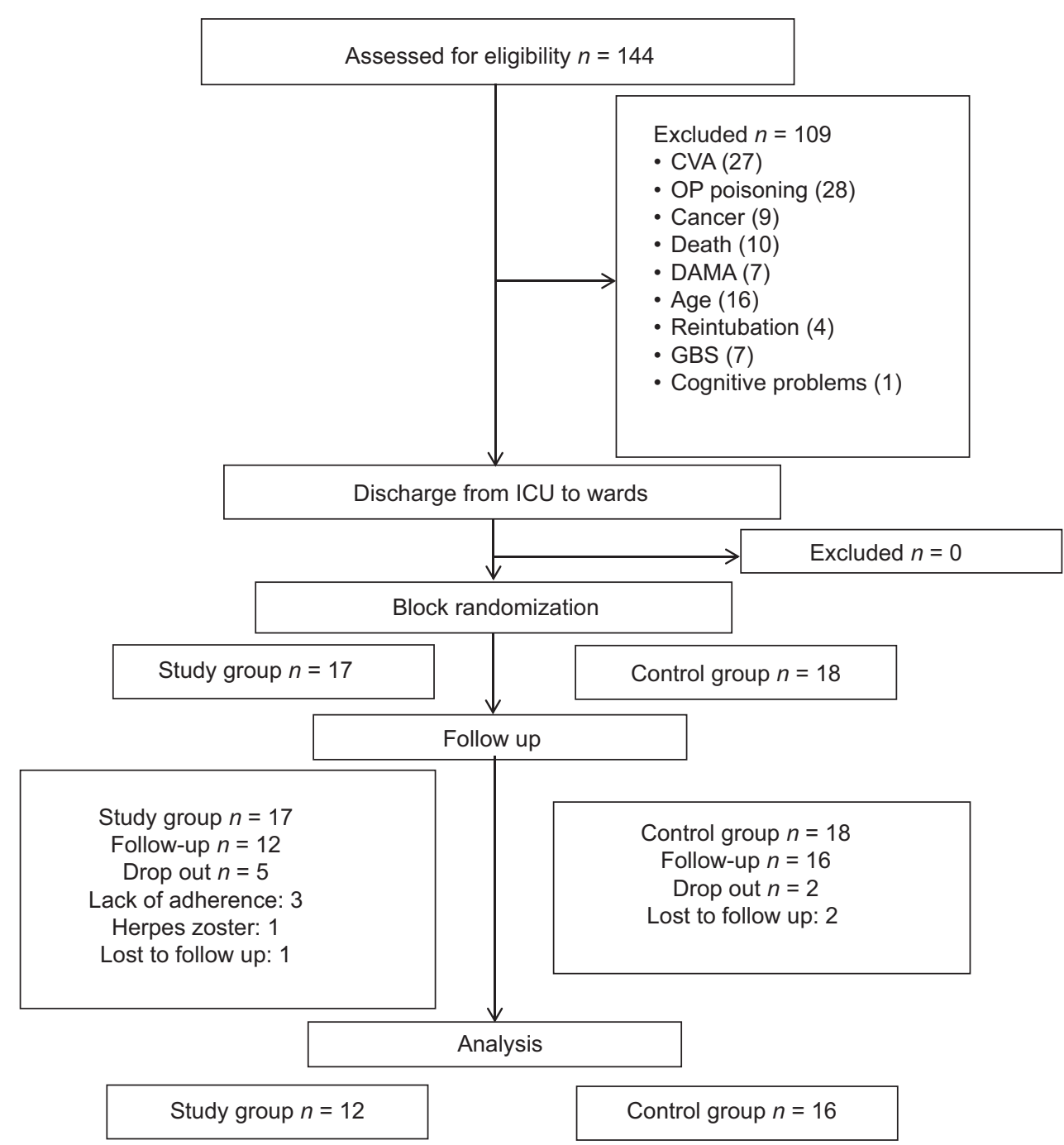

Figure 1: Flow chart of recruitment of participants following CONSORT guidelines.

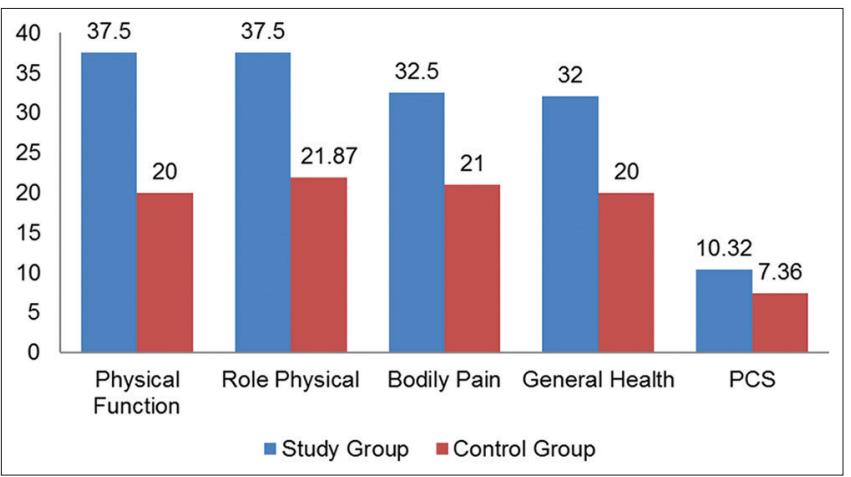

Figure 2: Median change in scores of domains of physical component between groups. PCS: Physical component summary.

and mental component in the study group compared to control group after 4 weeks of hospital discharge. The possible reason for these improvements could be because of spontaneous recovery over the period of 4 weeks. Another probable reason could be that subjects of the control group were benefited with the routine physiotherapy provided in the ICU and the wards. Furthermore, patients in the control group might have performed the exercises without the exercise information sheet. Hence with a maturity of time, a marked improvement in the physical and mental function would have occurred in the control group from their baseline status.

\section{Physical component and its domains}

At baseline, the median change in the scores from ICU discharge to hospital discharge was $2.99(2.20-4.57)$ and 1.83 (1.05-4.06), in study and control group, respectively, suggesting a similar trend of change in the QoL during the hospital stay. There was an improvement in the physical component and all its domains in the study group as compared to control group over a period of 4 weeks. The individually tailored and telephonically monitored exercises performed by the patients of the study group after hospital discharge might have had positive effects on their cardiopulmonary and musculoskeletal systems. Another study was done by Jones et al., similar results were found in a double-blinded randomized controlled trial where unsupervised, patient-directed home-based exercises for 6 weeks with printed rehabilitation manual and three follow-up 


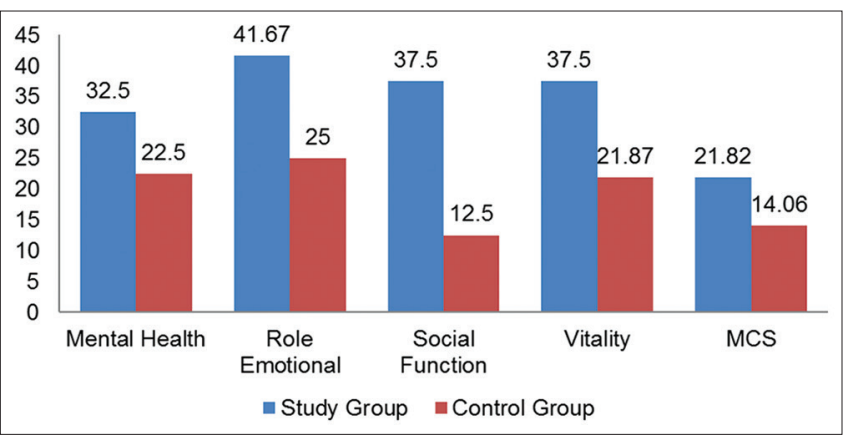

Figure 3: Median change in scores of domains of the mental component between groups. MCS: Mental component summary.

phone calls were given to patients in the intervention group in this study. Improvements only in the physical component were noted in this study at the end of 6 months. ${ }^{[8]}$

\section{Mental component and its domains}

The change in the MCS score before randomization was similar for both groups, i.e., 3.27 (1.81-6.55) and 2.91 (1.29-6.04) for study and control group, respectively. We found significant improvements in the mental component and all its domains after 4 weeks of home-based exercises in the study group. Physiologically, exercises increase the release of endorphins which in turn improves circulation and has an impact on a hypothalamic-pituitary-adrenal axis which collectively improves the physiological reactivity to stress. ${ }^{[9]}$ Hence, this could have improved the scores of MCS which corresponds to the anxiety and depression status $(r=0.88)^{[10]}$ of the participants in the study group. Another reason for this improvement could be the better physical functional status of the patients in the study group. Better functional status might have led to increment in the social participation and reduction in episodes of frustration, anxiety, and depression further improving their social and mental wellbeing. Contrary to the study conducted by Elliott $e t$ al. on critical care survivors, in which graded individualized exercise program was given for 8 weeks with five follow-up phone calls to the study group and usual care to the control group. They did not find statistically significant differences in 6-min walk test or HRQoL at 8 or 26 weeks after discharge. ${ }^{[1]}$ Similarly, in a single blinded study by Cuthbertson et al., manual-based physical rehabilitation program was given for 6 weeks to subjects in the study group. No improvement in PCS or MCS score was seen after 3 and 12 months probably because there were no measures taken to improve adherence to the exercise program which might have impaired the quality of an effective intervention. ${ }^{[12]}$

Even though all the participants of the study group were telephonically followed up every week and logbook was provided, only 12 out of 15 participants performed the exercises consistently over a period of 4 weeks after hospital discharge. Therefore, the adherence in our study population was $80 \%$. However, there was no difference between the group which adhered to the exercise and the group which did not adhere to the exercise at baseline. Our results from this study

\begin{tabular}{|c|c|c|c|}
\hline \multicolumn{2}{|c|}{ Study group ( $n=17)$} & \multicolumn{2}{|c|}{ Control group $(n=18)$} \\
\hline Clinical profile & $n(\%)$ & Clinical profile & $n(\%)$ \\
\hline COPD & $5(29.4)$ & COPD & $2(11.1)$ \\
\hline ARDS & $3(17.6)$ & ARDS & $4(22.2)$ \\
\hline Urosepsis & $2(11.8)$ & Urosepsis & $1(5.6)$ \\
\hline Acute pancreatitis & $1(5.8)$ & Acute pancreatitis & $2(11.1)$ \\
\hline Pulmonary edema & $2(11.8)$ & Acute respiratory failure & $3(16.7)$ \\
\hline CKD & $2(11.8)$ & Bronchial asthma & $2(11.1)$ \\
\hline Others & $2(11.8)$ & Others & $4(22.2)$ \\
\hline
\end{tabular}

COPD: Chronic obstructive pulmonary disease; ARDS: Acute respiratory distress syndrome; CKD: Chronic kidney disease

\begin{tabular}{|c|c|c|c|}
\hline \multirow[t]{2}{*}{ Domains } & \multicolumn{2}{|c|}{$\begin{array}{c}\text { Difference between scores at hospital } \\
\text { discharge and after } 4 \text { weeks Median (IQR) }\end{array}$} & \multirow[t]{2}{*}{$P$} \\
\hline & Experimental group & Control group & \\
\hline Physical function & $37.50(27.50-47.50)$ & $20.00(15.00-28.75)$ & 0.003 \\
\hline Role physical & $37.50(31.25-43.75)$ & $21.87(12.50-25.00$ & 0.001 \\
\hline Bodily pain & $32.50(22.00-33.00)$ & $21.00(10.00-21.00)$ & 0.004 \\
\hline General health & $32.00(18.50-37.00)$ & $20.00(12.75-27.00)$ & 0.017 \\
\hline PCS & $10.32(8.51-14.92)$ & $7.36(3.68-8.48)$ & 0.003 \\
\hline
\end{tabular}

PCS: Physical component summary; IQR: Interquartile range

\begin{tabular}{|c|c|c|c|}
\hline \multirow[t]{2}{*}{ Domains } & \multicolumn{2}{|c|}{$\begin{array}{l}\text { Difference between scores at hospital } \\
\text { discharge and after } 4 \text { weeks Median (IQR) }\end{array}$} & \multirow[t]{2}{*}{$P$} \\
\hline & Experimental group & Control group & \\
\hline Mental health & $32.50(25.00-40.00)$ & $22.50(16.25-25.00)$ & 0.008 \\
\hline Role emotional & $41.67(35.41-47.91)$ & $25.00(25.00-25.00)$ & 0.001 \\
\hline Social function & $37.50(25.00-50.00)$ & $12.50(25.00-25.00)$ & 0.008 \\
\hline Vitality & $37.50(23.43-43.75)$ & $21.87(18.75-29.68)$ & 0.003 \\
\hline MCS & $21.82(15.66-24.05)$ & $14.06(10.83-19.48)$ & 0.006 \\
\hline
\end{tabular}

MCS: Mental component summary; IQR: Interquartile range

would be useful for providing individualized rehabilitation sheet to patients postdischarge for a better understanding of the exercises so as to improve their functional status thereby improving their quality of life. Individualized home-based program can be beneficial and cost-effective for individuals who reside in rural areas as it eliminates the need to attend an outpatient clinic located in the tertiary hospital where they were treated. One limitation of this study was a long-term follow-up for 6 or 12 months was not done as the study was time bound.

\section{Conclusion}

From our present study, we can conclude, 4 weeks of home-based exercises is effective in improving the physical and mental components of health-related quality of life of ICU survivors. 


\section{Financial support and sponsorship}

Nil.

\section{Conflicts of interest}

There are no conflicts of interest.

\section{RefEREnCes}

1. Phua J, Badia JR, Adhikari NK, Friedrich JO, Fowler RA, Singh JM, et al. Has mortality from acute respiratory distress syndrome decreased over time?: A systematic review. Am J Respir Crit Care Med 2009;179:220-7.

2. Annane D,Aegerter P, Jars-Guincestre MC, Guidet B; CUB-Réa Network. Current epidemiology of septic shock: The CUB-Réa network. Am J Respir Crit Care Med 2003;168:165-72.

3. Tu JV, Nardi L, Fang J, Liu J, Khalid L, Johansen H; Canadian Cardiovascular Outcomes Research Team. National trends in rates of death and hospital admissions related to acute myocardial infarction, heart failure and stroke, 1994-2004. CMAJ 2009;180:E118-25.

4. Griffiths JA, Morgan K, Barber VS, Young JD. Study protocol: The intensive care outcome network ('ICON') study. BMC Health Serv Res 2008;8:132.

5. Davydow DS, Gifford JM, Desai SV, Bienvenu OJ, Needham DM. Depression in general intensive care unit survivors: A systematic review. Intensive Care Med 2009;35:796-809.
6. Griffiths J, Fortune G, Barber V, Young JD. The prevalence of post traumatic stress disorder in survivors of ICU treatment: A systematic review. Intensive Care Med 2007;33:1506-18.

7. Angus DC, Carlet J; Brussels Roundtable Participants. Surviving intensive care: A report from the 2002 Brussels roundtable. Intensive Care Med 2003;29:368-77.

8. Jones C, Skirrow P, Griffiths RD, Humphris GH, Ingleby S, Eddleston J, et al. Rehabilitation after critical illness: A randomized, controlled trial. Crit Care Med 2003;31:2456-61.

9. Guszkowska M. Effects of exercise on anxiety, depression and mood. Psychiatr Pol 2004;38:611-20.

10. Pfoh ER, Chan KS, Dinglas VD, Cuthbertson BH, Elliott D, Porter R, et al. The SF-36 offers a strong measure of mental health symptoms in survivors of acute respiratory failure. A tri-national analysis. Ann Am Thorac Soc 2016;13:1343-50.

11. Elliott D, McKinley S, Alison J, Aitken LM, King M, Leslie GD, et al. Health-related quality of life and physical recovery after a critical illness: A multi-centre randomised controlled trial of a home-based physical rehabilitation program. Crit Care 2011;15:R142.

12. Cuthbertson BH, Rattray J, Campbell MK, Gager M, Roughton S, Smith A, et al. The PRaCTICaL study of nurse led, intensive care follow-up programmes for improving long term outcomes from critical illness: A pragmatic randomised controlled trial. BMJ 2009;339:b3723. 